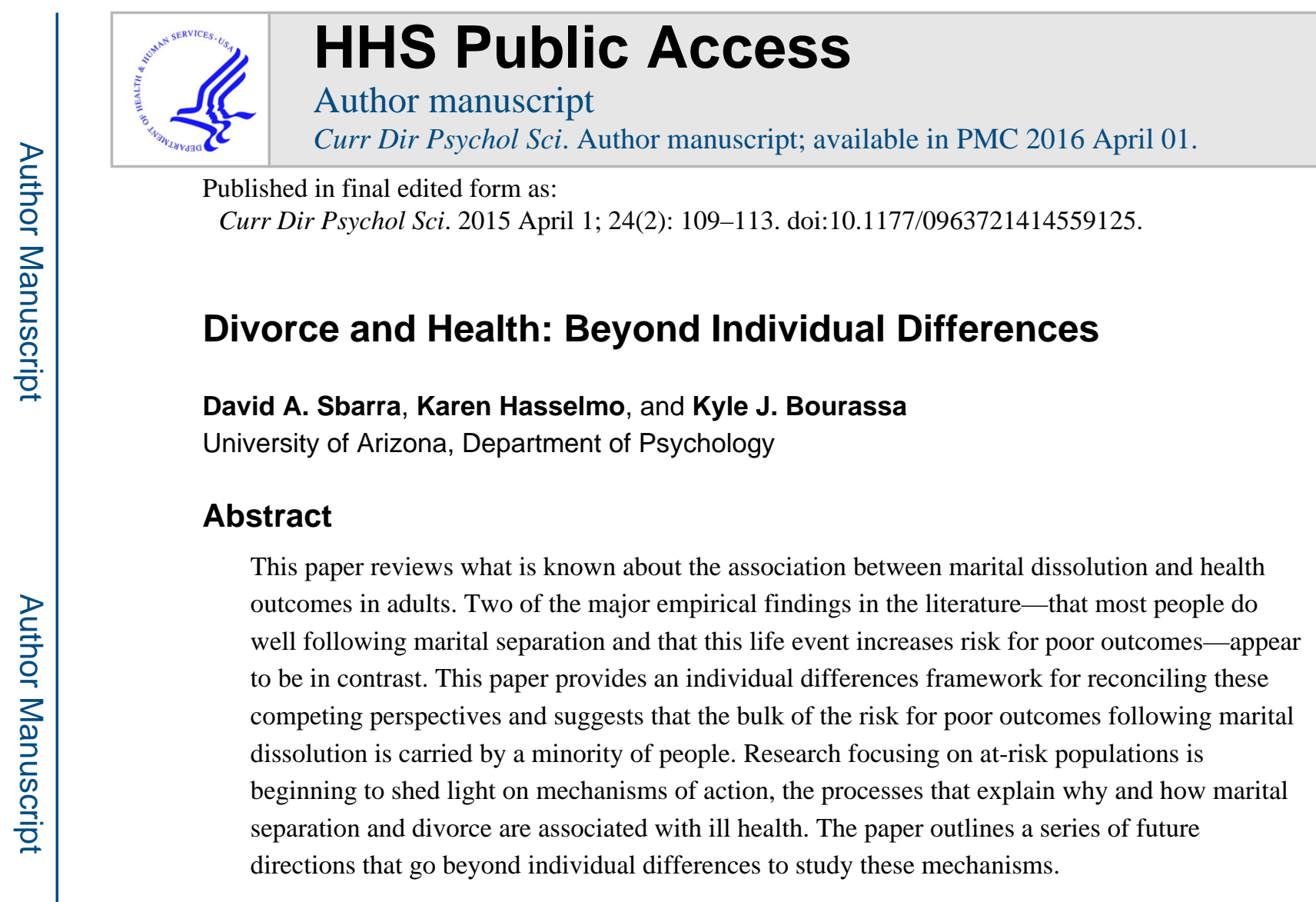

\title{
Keywords
}

Divorce; health; psychophysiology; diathesis-stress; relationships

For adults and children alike, the experience of marital separation and divorce is a significant source of stress and constitutes a major life transition. Even among people who report limited or transient disturbances in psychological wellbeing, the end of marriage is an upheaval that often entails a wide variety of challenges, including substantial financial changes and legal involvement, the renegotiation of parenting relationships and the management of co-parenting conflicts, changes in friendships and social networks, moving, as well as a host of psychological challenges. When marriage ends, many people face fundamental questions about their sense of self: Who am I without my partner? With 40$45 \%$ of first marriages ending in divorce (Kreider \& Ellis, 2011) and approximately 2.5 million adults newly impacted by the end of marriage each year (Arias, 2007), efforts to understand exactly who fares well or poorly following marital separation are of considerable public health significance.

Such efforts focus squarely on individual differences, the idea that people vary in their response to negative life events like divorce, but that this variability is systematic and can be predicted from relevant variables such as personality, sex, or relationship history. The central idea of this paper is that some people are at substantial risk for poor outcomes when marriage ends and studying individual differences following marital separation provides

Correspondence concerning this paper can be addressed to David A. Sbarra (sbarra@email.arizona.edu), 1503 East University Blvd, Rm 312, Tucson, Arizona 85721-0068, Fax: 520-621-9306, or Phone: 520-626-6426.

The authors declare no conflicts of interest. 
important clues about the processes, or the mechanisms of action, that help explain why divorce is associated with poor health outcomes. ${ }^{1}$ Said differently, by identifying who suffers the most when a relationship ends, then characterizing how these people behave in response to their separation, we may begin to understand why and how divorce conveys risk for poor outcomes.

\section{Resilience and Risk}

The empirical study of adults' bio-psycho-social responses to marital separation and divorce has generated two fairly reliable facts that, on the surface, appear to be in clear opposition. First, most people are psychologically resilient and fare quite well following divorce (Amato, 2010; Hetherington \& Kelly, 2002). A large, prospective study of German adults, for example, demonstrated that the vast majority of people-nearly $72 \%$ of over 600 divorces-experienced little self-reported change in life satisfaction across a 9-year period that included the divorce (Mancini, Bonanno, \& Clark, 2011). Consistent with the general tendency toward human resilience in the face of stress, positive - or at least nonpathological - outcomes are the norm following divorce, not the exception, and this appears true for both children and adults (Emery, 2006; Perrig-Chiello, Hutchison, \& Morselli, 2014).

The second observation is that becoming separated/divorced is associated with long-term decreases in life satisfaction (Lucas, 2005) and heightened risk for a range of illnesses (Björkenstam, Hallqvist, Dalman, \& Ljung, 2013), poor disease outcomes among the already ill (Floud et al., 2014), and even for early death (Lund, Christensen, Evald Holstein, Due, \& Osler, 2006). Two recent meta-analyses, involving 6.5 million people (Sbarra et al., 2011) and 600 million (Shor, Roelfs, Bugyi, \& Schwartz, 2012), respectively, suggest that divorced adults experience a $20-30 \%$ increase in risk for early death relative to their married counterparts. This relative risk effect size is comparable to many other public health risks, such as obesity, lack of regular exercise, and excessive alcohol intake (cf. Holt-Lunstad, Smith, \& Layton, 2010).

Considering these two observations side by side raises an important question: How can it be that most divorced adults are resilient, yet these same people are also at risk for early death? If some people suffer much more than others when marriage ends, it is quite possible for an average effect to suggest that exposure to divorce is associated with poor outcomes while the modal response is a quick return to life as normal. These contrasting findings do not render either effect meaningless; instead, the evidence for both risk and resilience requires refined research on the variables (i.e., individual differences) that predict good or poor outcomes.

\footnotetext{
${ }^{1}$ We use the term health broadly to discuss a range of outcomes—-from depression to cardiovascular disease—-that reflect substantial functional impairment and diminished quality of life. Although it is likely that some variables predict psychological or mental health outcomes and others predict health-relevant biology and disease outcomes, a broad perspective on health outcomes provides the best overview of the literature.
} 


\section{Individual Differences Matter}

In the study of divorce and health, it appears that a relatively small percentage of adultsperhaps $15-20 \%$ of people-fare quite poorly when their marriage comes to an end (Mancini et al., 2011). Who are these people and what factors place them at risk for poor outcomes? In many instances, it is difficult to determine whether divorce plays a direct causal role in the emergence of health problems, or whether third variables (e.g., hostility) predict the likelihood of both divorce and its putative outcomes (Amato, 2010). Is the stress and strain of ending a marriage playing a key causal role in driving the putative health consequences of divorce? Co-twin control studies, for example, are one method that can help inform our understanding of causality (cf. Jocklin, McGue, \& Lykken, 1996); comparing health outcomes between identical twins who share $100 \%$ of their genetic material but who differ in the experience of divorce is a powerful method for isolating environmental influences. Ultimately, it is likely that the health correlates of divorce will be best understood in terms of a larger diathesis-stress framework in which some people, even after accounting for the factors that select them out of marriage, remain vulnerable and suffer prolonged distress as a consequence of the separation experience.

This point is consistent with a recent prospective study demonstrating that the effects of divorce on the probability of future rates of major depressive disorder (MDD) depended almost entirely on adults' history of MDD (Sbarra, Emery, Beam, \& Ocker, 2013). As shown in Figure 1, for people without a history of MDD, the experience of marital separation and divorce do not significantly elevate risk for a future depressive episode. In contrast, roughly 6 out of 10 people with a history of MDD who also became divorced (during the period between the two assessments) experienced a subsequent depressive episode. In this study, risk of poor mental health outcomes after divorce was limited to people who had struggled emotionally prior to the end of marriage.

In terms of psychological characteristics associated with adjustment to divorce, individual differences in attachment anxiety are associated with poor outcomes when people perceive a threat to their relationship and/or to their security within the relationship (Davis, Shaver, \& Vernon, 2003). People high in attachment anxiety tend to be hyper-sensitive to relationship themes and, when a relationship ends, often engage in repetitive attempts to reunite with an ex-partner or become preoccupied with why the relationship ended. These behaviors have health relevance. Lee, Sbarra, Mason, and Law (2011) found that recently separated adults who were high in attachment anxiety and who spoke about their separation in a very personal, present-oriented, "here-and-now" manner (presumably reflecting a high degree of attachment-related preoccupation with the loss), evidenced the greatest blood pressure reactivity when asked to think about their separation experience.

People high in anxiety become psychologically immersed in their experiences, and this process is associated with the greatest cardiovascular activity when people reflect over their separation. Difficulty creating distance from one's experience is the hallmark of psychological rumination, the tendency to reflect over experiences in a negative, selffocused, and overly general way (Nolen-Hoeksema, Wisco, \& Lyubomirsky, 2008), and other recent evidence suggests that people with a tendency toward rumination struggle the 
most when they are asked to think deeply about their separation. Separated adults reporting a high degree of rumination evidenced increases in separation-related emotional distress three months after engaging in a three session expressive writing intervention that encouraged them to express their emotions about the separation event (Sbarra, Boals, Mason, Larson, \& Mehl, 2013). When assigned to control writing, which asked participants to write in a concrete, non-emotional way about how they had spent and would spend their time in the next few days, high ruminators reported the lowest levels separation-related emotional distress eight months later.

\section{Beyond Individual Differences and Toward Psychosocial Explanations}

The three studies reviewed above provide only a small picture of the many individual differences that predict risk for poor outcomes following divorce (see Amato, 2010; Mason $\&$ Sbarra, 2012). Taken together, however, the research on pre-divorce depression, attachment anxiety, and the effects of expressive writing for ruminators begins to point beyond the study of individual differences to provide some important clues about the potential mechanisms (i.e., psychosocial explanations) linking marital separation to poor outcomes. For example, following marital separation, people who have a hard time distancing themselves from their psychological experiences show excessive cardiovascular reactivity, which, if maintained over time, is associated with the development of cardiovascular disease (Chida \& Steptoe, 2010). Conceptually, this work fits well with the larger literature on self-distanced reflection and evidence indicating that people who recount their experiences in a blow-by-blow manner rather than reconstrue their experiences to find meaning, are at heightened risk for mood disorders (Kross, Gard, Deldin, Clifton, \& Ayduk, 2012). One way in which people may remain stuck following their separation is to become over-involved and immersed in their experiences - to ruminate and recount all that is bad and will be terrible going forward (cf. Sbarra, Smith, \& Mehl, 2012) ${ }^{2}$

We have suggested that the ability to gain a self-distanced perspective on one's separation may be an important variable linking the end of marriage to health, but it is certainly not the only variable that explains distal outcomes. ${ }^{3}$ Chronic psychological stress has healthcompromising effects, and any efforts to understand pathways of action must consider divorce-specific variables above-and-beyond general psychological stress and loneliness (see Sbarra \& Hazan, 2008). We suggest three additional variables (two psychological and one behaviorial) deserve further consideration in this regard. Some of the earliest immunological work on divorce focused on attachment to/longing for an ex-partner (Kiecolt-Glaser, Fisher, Ogrocki, Stout, \& et al., 1987). This research found that ongoing attachment to an ex-spouse was associated with impairments in cellular immune responses (e.g., antibody titers to latent herpesvirus) and remains one of the only investigations of the ways in which psychological responses to marital separation may be associated with health-

\footnotetext{
${ }^{2}$ This point has relevance beyond the study of divorce and applies to understanding how people cope with a range of stressful life events. Because marital separation and divorce provoke strong emotions, many of which are social in nature (e.g., shame, humiliation), the inability to gain distance from one's experience may be a strong predictor of poor outcomes. This fact does not imply that self-distanced reflection is more important following divorce than any other stressful life event. For a discussion of ways in which divorce is similar to and different from other stressful life events, including the loss of a partner through death, see Sbarra and Hazan (2008) and Sbarra et al. (2013).

${ }^{3}$ Sbarra et al. (2011) provide a detailed discussion of potential mechanisms explaining the association between divorce and death.
} 
relevant immunological changes. The field needs much more research linking psychological responses to divorce to biomarkers that have direct relevance for health; simply studying physiology as a marker of health relevance is not enough, and a number of researchers have called for the need to investigate biologically plausible pathways from life stress to disease outcomes (Miller, Chen, \& Cole, 2009).

Beyond self-distanced reflection and longing, other variables and processes may serve as potential explanatory pathways leading to health-relevant biological changes. In a prospective study of breakups following non-marital dissolution (Mason, Law, Bryan, Portley, \& Sbarra, 2012), improvements in self-concept clarity (knowing who you are as a person after a separation) were associated with increases in future psychological wellbeing (also see Slotter, Gardner, Finkel, 2010). There was no evidence in this study that people begin to feel better, then report a greater sense of who they are after their breakup; instead, the direction of the effect seems to operate from self-concept clarity to improved psychological wellbeing. Self-concept clarity was a key variable in early accounts of the psychological response to divorce (Weiss, 1975), yet no studies to date have examined this variable with respect to biomarkers of interest.

Given well-known theories regarding the social control of health behaviors (Umberson, 1992), it is also important to investigate whether and how the end of marriage is associated with changes in health-promoting and/or health-compromising behaviors. Sleep, for example, is a salubrious health behavior that affects nearly every aspect of psychological functioning, and sleep problems are linked to a variety of physical morbidities. With respect to divorce outcomes, a recent study demonstrated sleep problems lasting longer than 10 weeks after marital separation were associated with future increases in resting blood pressure (Krietsch, Mason, \& Sbarra, in press). This work suggests that sleep problems that extend beyond a few months after the physical separation may presage worsening physical health. Sleep is one of many health-promoting and/or -compromising behaviors that could link divorce to pathophysiology, and future research will benefit by studying how psychological responses to divorce work in tandem with changes in health behaviors to predict long-term outcomes.

One obvious limitation of this discussion is that the variables we have proposed as important mechanisms of change are largely psychological, and not particularly interpersonal or behavioral. How do people spend their time after a separation? How do ex-partners interact in the weeks and months after ending their marriage? What interpersonal processes or exchanges are particularly relevant for health when marriage ends? It is increasingly clear that efforts to move beyond individual differences must also entail efforts to move beyond intrapersonal variables and to consider the social processes that convey (or protect against) risk for poor outcomes (see Sbarra \& Emery, 2008).

\section{Conclusion}

Although most people are resilient in the face of divorce, some people suffer enormously when marriage comes to an end. This paper reviewed several studies describing who is at greatest risk for poor outcomes following the end of marriage. In doing so, we suggested 
that by studying individual differences in the variables that confer risk, we may begin to understand the psychosocial pathways that explain why and, perhaps how, divorce is associated with poor outcomes. Our analysis described work in several areas, including the importance of self-immersion and self-distanced reflection, the study of longing, selfconcept clarity, and, finally, the importance of sleep and disturbances in the wake of a separation. A key challenge for future research is to begin asking mechanistic questions that link psychosocial variables germane to the end of marriage with health-relevant biomarkers.

\section{Acknowledgments}

The first author's work on this paper was supported in part by grants from the National Institute of Child Health and Human Development (HD\#069498) and the National Institute on Aging (AG\#036895).

\section{References}

Amato PR. Research on divorce: Continuing trends and new developments. Journal of Marriage \& Family. 2010; 72:650-666. A cogent review paper discussing the major theories and empirical findings in the study of divorce.

Arias, E. National Vital Statistics Reports. Vol. 56. Hyattsville, MD: National Center for Health Statistics; 2007. United States Life Tables, 2004.

Björkenstam E, Hallqvist J, Dalman C, Ljung R. Risk of new psychiatric episodes in the year following divorce in midlife: Cause or selection? A nationwide register-based study of 703,960 individuals. International Journal of Social Psychiatry. 2013; 59:801-804. [PubMed: 23071000]

Chida Y, Steptoe A. Greater cardiovascular responses to laboratory mental stress are associated with poor subsequent cardiovascular risk status a meta-analysis of prospective evidence. Hypertension. 2010; 55:1026-1032. [PubMed: 20194301]

Davis D, Shaver PR, Vernon ML. Physical, emotional, and behavioral reactions to breaking up: The roles of gener, age, environmental involvement, and attachment style. Personality \& Social Psychology Bulletin. 2003; 29:971-884.

Emery, RE. The truth about children and divorce: Dealing with the emotions so you and your children can thrive. New York: Penguin; 2006.

Floud S, Balkwill A, Canoy D, Wright FL, Reeves GK, Green J, Cairns BJ. Marital status and ischemic heart disease incidence and mortality in women: A large prospective study. BMC Medicine. 2014; 12:42.10.1186/1741-7015-12-42 [PubMed: 24618083]

Hetherington, EM.; Kelly, J. For better or for worse: Divorce reconsidered. New York: Norton \& Company; 2002.

Holt-Lunstad J, Smith T, Layton J. Social relationships and mortality risk: A meta-analytic review. Public Library of Medicine. 2010; 1000316(7):e1000316.

Jocklin V, McGue M, Lykken DT. Personality and divorce: A genetic analysis. Journal of Personality and Social Psychology. 1996; 71:288-299. [PubMed: 8765483]

Kiecolt-Glaser JK, Fisher LD, Ogrocki P, Stout JC, et al. Marital quality, marital disruption, and immune function. Psychosomatic Medicine. 1987; 49:13-34. [PubMed: 3029796]

Kreider, RM.; Ellis, R. Number, timing, and duration of marriages and divorces: 2009. US Department of Commerce, Economics and Statistics Administration, US Census Bureau; 2011.

Kriegbaum M, Christensen U, Lund R, Osler M. Job losses and accumulated number of broken partnerships increase risk of premature mortality in danish men born in 1953. Journal of Occupational and Environmental Medicine. 2009; 51:708. [PubMed: 19430317]

Krietsch KN, Mason AE, Sbarra DA. Sleep complaints predict increases in resting blood pressure following marital separation. Health Psychology. (in press).

Kross E, Gard D, Deldin P, Clifton J, Ayduk O. “Asking why” from a distance: Its cognitive and emotional consequences for people with major depressive disorder. Journal of Abnormal Psychology. 2012; 121:559-569. [PubMed: 22708885] 
Lee LA, Sbarra DA, Mason AE, Law RW. Attachment anxiety, verbal immediacy, and blood pressure: Results from a laboratory analog study following marital separation. Personal Relationships. 2011; 18:285-301. [PubMed: 21647240]

Lorenz FO, Simons RL, Conger RD. Married and recently divorced mothers' stressful events and distress: Tracing change across time. Journal of Marriage \& the Family. 1997; 59:219-232.

Lucas RE. Time does not heal all wounds: A longitudinal study of reaction and adaptation to divorce. Psychological Science. 2005; 16:945-950. [PubMed: 16313658]

Lund R, Christensen U, Evald Holstein B, Due P, Osler M. Influence of marital history over two and three generations on early death. A longitudinal study of danish men born in 1953. Journal of Epidemiology and Community Health. 2006; 60:496-501. [PubMed: 16698979]

Mancini AD, Bonanno GA, Clark AE. Stepping off the hedonic treadmill. Journal of Individual Differences. 2011; 32:144-152.

Mason AE, Law RW, Bryan AE, Portley RM, Sbarra DA. Facing a breakup: Electromyographic responses moderate self-concept recovery following a romantic separation. Personal Relationships. 2012; 19:551-568.

Mason, AE.; Sbarra, D. Romantic separation, loss, and health: A review of moderators. In: Newman, M.; Roberts, N., editors. Handbook of Health and Social Relationships. Washington, DC: American Psychological Association; 2012. p. 95-120.

Mikulincer, M.; Shaver, PR. Attachment in adulthood: Structure, dynamics, and change. New York, NY, US: Guilford Press; 2007.

Miller GE, Chen E, Cole SW. Health psychology: Developing biologically plausible models linking the social world and physical health. Annual review of Psychology. 2009; 60:501-524. An excellent review and framework for understanding how social processes can impact physiological systems to exert biologically plausible effects on disease endpoints.

Nolen-Hoeksema S, Wisco BE, Lyubomirsky S. Rethinking rumination. Perspectives on Psychological Science. 2008; 3:400-424.

Osler M, McGue M, Lund R, Christensen K. Marital status and twins' health and behavior: An analysis of middle-aged dDanish twins. Psychosomatic Medicine. 2008; 70:482-487. [PubMed: 18480194]

Perrig-Chiello P, Hutchison S, Morselli D. Patterns of psychological adaptation to divorce after a longterm marriage. Journal of Social and Personal Relationships. 2014:0265407514533769.

Sbarra DA, Boals A, Mason AE, Larson GM, Mehl MR. Expressive writing can impede emotional recovery following marital separation. Clinical Psychological Science. 2013; 1:120-134. [PubMed: 25606351]

Sbarra DA, Emery RE, Beam CR, Ocker BL. Marital dissolution and major depression in midlife: A propensity score analysis. Clinical Psychological Science. 2013; 2:249-257.

Sbarra DA, Emery RE. Deeper into divorce: Using actor-partner analyses to explore systemic differences in coparenting following mediation and litigation of custody disputes. Journal of Family Psychology. 2008; 22:144-152. [PubMed: 18266541]

Sbarra DA, Hasselmo K, Nojopranoto W. Divorce and death: A case study for health psychology. Social and Personality Psychology Compass. 2012; 6:905-919. This paper reviews the topics covered here in more detail, including a discussion of novel research designs. [PubMed: 23284588]

Sbarra DA, Law RW, Portley RM. Divorce and death: A meta-analysis and research agenda for clinical, social, and health psychology. Perspectives on Psychological Science. 2011; 6:454-474.

Sbarra DA, Smith HL, Mehl MR. When leaving your ex, love yourself: Observational ratings of selfcompassion predict the course of emotional recovery following marital separation. Psychological Science. 2012; 23:261-269. [PubMed: 22282874]

Sbarra DA, Nietert PJ. Divorce and death: Forty years of the Charleston Heart Study. Psychological Science. 2009; 20:107-113. [PubMed: 19076315]

Slotter EB, Gardner WL, Finkel EJ. Who am I without you? The influence of romantic breakup on the self-concept. Personality and Social Psychology Bulletin. 2010; 36:147-160. [PubMed: 20008964] 
Shor E, Roelfs DJ, Bugyi P, Schwartz JE. Meta-analysis of marital dissolution and mortality: Reevaluating the intersection of gender and age. Social Science \& Medicine. 2012; 75:46-59. [PubMed: 22534377]

Umberson D. Gender, marital status and the social control of health behavior. Social Science \& Medicine. 1992; 34:907-917. [PubMed: 1604380]

Weiss, RS. Marital separation. New York: Basic Books; 1975. 


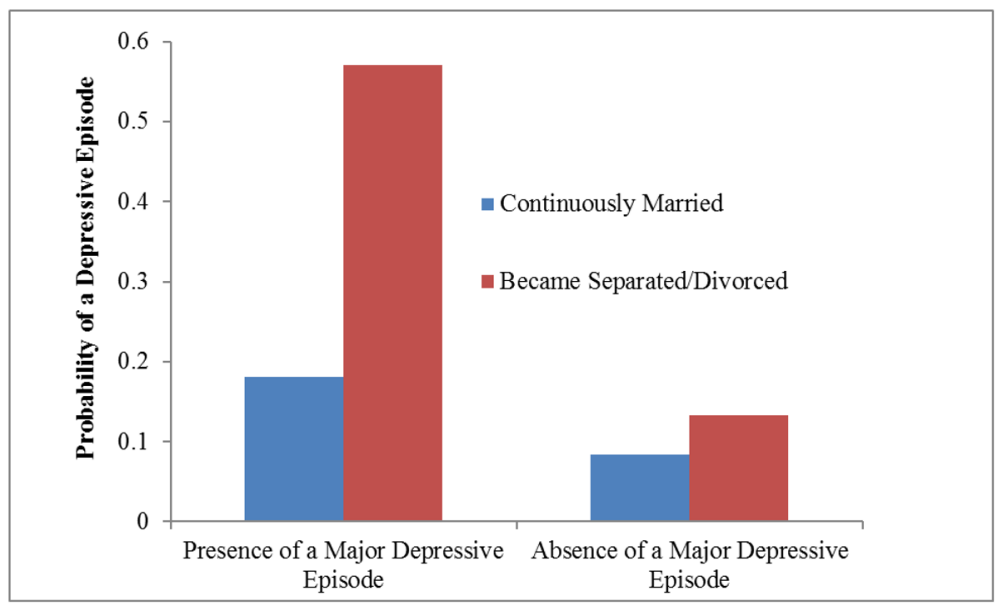

Figure 1.

Probability of a Major Depressive Episode (MDE) in the second wave of the Midlife in the United States (MIDUS) Study (M2) as a function of participants' marital status and depression at the first MIDUS assessment (M1). The greatest risk for a MDE was observed among people who experienced a separation/divorce between M1 and M2 and who also experienced a MDE at M1. The figure is reproduced from Sbarra et al. (2013). 